\title{
Animal político. \\ Aristóteles, Arendt y nosotros ${ }^{1}$
}

\author{
(Political animal. \\ Aristotle, Arendt and us)
}

Antonio CAMPILlO

Recibido: 13 de mayo de 2013

Aceptado: 7 de octubre de 2013

\section{Resumen}

En este artículo se revisa la definición aristotélica del ser humano como "animal político", a la luz de los cambios que ha experimentado la condición humana en los dos últimos siglos. En concreto, se lleva a cabo una lectura de Aristóteles desde Arendt, y de Arendt desde Aristóteles. Mediante esta doble lectura crítica, se plantea la necesidad de elaborar una antropología bio-tecno-política, que evite la disyuntiva entre el dualismo metafísico-teológico y el monismo físico-biológico.

Palabras clave: vida, muerte, política, libertad, naturaleza, técnica, Aristóteles, Arendt.

\section{Abstract}

In this article I examine the Aristotelian definition of the human being as "political animal" in the light of the changes human condition has experienced in the last two centuries. Specifically, I make an interpretation of Aristotle based on Arendt's

\footnotetext{
${ }^{1}$ Una primera versión de este artículo fue presentada el 6/11/2012 en el Simposio Arendt en diálogo con los desafios de hoy, coordinado por Cristina Sánchez (Universidad Autónoma de Madrid) y María José López (Universidad de Chile), en el marco del IV Congreso Iberoamericano de Filosofía: Filosofía en Diálogo, organizado por la Sociedad de la Enciclopedia Iberoamericana de Filosofía, la Facultad de Filosofía de la Pontificia Universidad Católica de Chile y la Facultad de Filosofía y Humanidades de la Universidad de Chile, y celebrado del 5 al 9 de noviembre de 2012, en Santiago de Chile.
} 
work and an interpretation of Arendt based on Aristotle's work. Throughout this double critical review I suggest that we need to develop a bio-techno-political anthropology that avoids the dilemma between the metaphysical-theological dualism and the physical-biological monism.

Keywords: life, death, politics, freedom, nature, technique, Aristotle, Arendt.

La relación entre vida y política se ha convertido en el eje de rotación en torno al cual giran muchos de los debates filosóficos contemporáneos. ¿Por qué? Porque se ha producido una doble mutación histórica: por un lado, los límites de la llamada "naturaleza humana", que durante milenios habían sido considerados infranqueables e inmutables, han comenzado a ser franqueados y modificados, debido a la invención de nuevos medios tecno-políticos de destrucción y reproducción de la vida; por otro lado, los límites de la comunidad política, que durante milenios habían sido restringidos al gobierno coactivo ejercido por una pequeña élite sobre una población y un territorio más o menos circunscritos, también han comenzado a ser cuestionados y desplazados, debido a un proceso de politización de todas las esferas de la vida y de todas las escalas espaciales y temporales de interacción social, tecnológica y ecológica.

Esta doble mutación histórica fue reconocida por Hannah Arendt ya en los años cincuenta del siglo XX, primero en Los orígenes del totalitarismo y después en La condición humana, como el nuevo horizonte histórico de la humanidad y, por tanto, como el punto de partida de su propia reflexión filosófica. ${ }^{2}$ Pues bien, en las últimas décadas ha proseguido esa doble mutación, y hoy podemos hablar ya de la biosfera terrestre como de un gran laboratorio experimental en el que nuevos conocimientos tecno-científicos y nuevos procedimientos socio-políticos están permitiendo disponer de la vida y la muerte de todos los seres vivientes, incluida la propia especie humana. ${ }^{3}$

Este "gran experimento" planetario nos exige repensar la condición humana, y en especial la vieja definición aristotélica del ser humano como "animal político". A esto se refería Michel Foucault a mediados de los años 1970, cuando utilizó el concepto de "biopolítica". No pretendo abordar aquí el debate que se ha producido

\footnotetext{
2 Arendt (1981 y 1993). Véase el prólogo de La condición humana, pp. 13-19, y los dos parágrafos finales ("La vida como bien supremo" y "La victoria del animal laborans"), en especial p. 297, donde Arendt alude expresamente al doble poder adquirido por el ser humano en la segunda mitad del siglo XX, y que hasta ahora se consideraba prerrogativa exclusiva de la divinidad: el "poder de destrucción" de toda la vida terrestre y el "poder de creación" de nuevas formas de vida.

3 Campillo (2001), pp. 75-91.
} 
en torno a ese concepto, puesto que ya lo he hecho en otro lugar. 4 Me limitaré a citar la importante tesis de Foucault, en la que se hace mención al "animal político" de Aristóteles y a la nueva relación que el Occidente moderno comenzó a establecer entre vida y política:

Lo que se podría llamar "umbral de modernidad biológica" de una sociedad se sitúa en el momento en que la especie entra como apuesta del juego en sus propias estrategias políticas. Durante milenios, el hombre siguió siendo lo que era para Aristóteles: un animal viviente y además capaz de una existencia política; el hombre moderno es un animal en cuya política está puesta en entredicho su vida de ser viviente. ${ }^{5}$

No voy a comentar ahora la tesis de Foucault sobre el nacimiento de la biopolítica en el Occidente moderno. La he citado solamente para poner de manifiesto que los debates contemporáneos sobre la relación entre vida y política no se producen por casualidad, sino porque responden a cambios históricos muy profundos. $\mathrm{Si}$ Foucault se remonta a la formación del Estado soberano y del capitalismo moderno en los siglos XVII y XVIII, yo voy a recordar los cambios que han tenido lugar desde mediados del siglo XX. Mencionaré los cuatro cambios que considero más relevantes para repensar la relación entre vida y política. En La condición humana, Hannah Arendt se había referido solamente a los dos primeros. Quiero insistir en el hecho de que todos estos cambios son a un tiempo tecno-científicos y socio-políticos, es decir, que no habrían podido acontecer efectivamente sin una estrecha interconexión entre saber y poder, entre ciencia y política, entre instrumentos técnicos y procedimientos organizativos:

1. La invención de nuevos medios tecno-políticos para matar a los seres humanos, con un poder de destrucción hasta ahora desconocido: por un lado, los Estados "totalitarios" y los campos de exterminio; por otro lado, las armas de destrucción masiva y las guerras "totales", que no distinguen entre objetivos militares y civiles, y que pueden destruir ciudades, naciones enteras e incluso a toda la humanidad.

2. La invención de nuevos medios tecno-políticos para la selección genética, la reproducción artificial, la crianza masiva y la utilización funcional de toda clase de seres vivos. La biosfera terrestre se ha convertido en un inmenso laboratorio de experimentación, selección y domesticación de plantas, animales y humanos.

3. La invención de nuevos medios tecno-políticos para la extracción, transformación, distribución, consumo y contaminación de los "recursos naturales" (tierra, agua, aire, bosques, animales, etc.), vinculada al crecimiento ilimitado del capitalismo moderno. Este "crecimiento ilimitado" está provocando el agotamiento de los recursos, la pérdida de biodiversidad y el calentamiento global de la atmósfera,

\footnotetext{
4 Campillo (2010).

5 Foucault (1978), pp. 161-194. La cita corresponde a la p. 173.
} 
todo lo cual es una amenaza para la convivencia e incluso la supervivencia de la humanidad.

4. La invención de nuevos medios tecno-políticos que facilitan, en una escala y con una velocidad sin precedentes, el transporte y la comunicación entre individuos y grupos humanos que se encuentran diseminados por toda la Tierra. Esto está provocando la relativización de las viejas fronteras políticas, lingüísticas, étnicas, religiosas, etc., pero también la aparición de nuevas comunidades diseminadas y nuevas jerarquías sociales en función del mayor o menor acceso a las redes globales de transporte y comunicación. En otras palabras, se está formando una sola sociedad global de facto, pero no de iure. Por eso, el gran reto político del siglo XXI es la creación de instituciones y legislaciones que hagan posible una democracia cosmopolita.

Todos estos cambios históricos - cuya combinación ha dado lugar a lo que hoy se conoce como el proceso de globalización de todas las relaciones sociales, tecnológicas y ecológicas- están alterando los límites y las posibilidades vitales no solo de cada ser humano singular, y no solo de comunidades locales, naciones y civilizaciones enteras, sino de toda la humanidad viviente. Por eso, nos obligan a repensar radicalmente nuestra propia condición humana, y en especial las relaciones entre nuestra condición de seres vivientes y nuestra condición de seres políticos.

Se suele dar por supuesto que la condición a un tiempo biológica y política del ser humano fue postulada ya por Aristóteles, en el libro I de su Política, al hacer esta doble afirmación: “...que la pólis ["la ciudad como comunidad política”, según dice el propio autor al comienzo del libro: pólis kaì hē koinōnía hē politiké] es una realidad natural y que el ser humano [el autor emplea la palabra ánthrōpos y por tanto se refiere a los dos géneros de la especie humana: varón (anér) y mujer (gyné)] es por naturaleza un animal político (physei hē pólis estí, kai hóti ánthrōpos physei politikòn zōion)". 6 Sin embargo, estas dos afirmaciones están ligadas a toda una serie de presupuestos ontológicos y antropológicos que nosotros, hoy, no podemos dejar de poner en cuestión. Cuando digo "nosotros", me refiero a la humanidad viviente que en las últimas décadas se está constituyendo, por vez primera en la historia, como una sola sociedad global. ${ }^{7} \mathrm{Y}$, en efecto, la definición del ser humano como zôion politikón (animal político) fue limitada por el propio Aristóteles en un triple sentido:

\footnotetext{
6 Aristóteles, Política 1253a 1-3. Para la traducción, he tenido en cuenta la edición bilingüe griegoespañol de María Araujo y Julián Marías (1983), la bilingüe griego-francés de Jean Aubonnet (1971) y las españolas de Manuela García Valdés (1988) y de Carlos García Gual y Aurelio Pérez Jiménez (2004).

7 Campillo (2001), pp. 179-197.
} 
En primer lugar, fue restringida a los helenos que eran a un tiempo varones, cabezas de familia, propietarios de tierras y ciudadanos libres. Quedaban excluidos los bárbaros, los extranjeros, las mujeres, los niños, los pobres y los esclavos. La condición de "animal político" la poseen solo los varones helenos que son a un tiempo ciudadanos de una pólis, dueños de una hacienda y jefes de una familia. Ahora bien, dado que Aristóteles define la condición humana como condición política, al restringir el estatuto político de ciudadanía, restringe también la cualificación humana, o al menos establece una escala de humanidad, en cuya cúspide se encuentra el "animal político" heleno.

En segundo lugar, la definición del ser humano como "animal político" está subordinada a una segunda definición que Aristóteles vincula inseparablemente con la primera: la de "animal dotado de lógos" (zôion lógon échon). Para Aristóteles, el lógos es algo más que lenguaje: a diferencia de la voz animal (phōné), que solo expresa placer y dolor, el lenguaje humano está vinculado a la ley común y al conocimiento teorético. Por un lado, está vinculado a la ley común, porque el ser humano es el único animal que gracias al lenguaje puede discriminar entre lo útil y lo perjudicial, lo bueno y lo malo, lo justo y lo injusto, y por tanto instaurar leyes comunes y fundar sobre ellas la familia (oíkos) y la ciudad (pólis) como comunidades propiamente humanas. ${ }^{8}$

Por otro lado, el lógos humano, a diferencia de la phōné animal, está vinculado al conocimiento verdadero, epistémico o teorético (y no solo al conocimiento dóxico, fronésico o pragmático), porque gracias a él se forman las ciencias particulares $\mathrm{y}$, en especial, la filosofía, a la que Aristóteles llama "ciencia capital" (kefalên échousa epistémē) y "sabiduría" (sophía) ${ }^{9}$, pero también "ciencia universal" (kathólou epistémên), "ciencia libre" (mónēn eleytheran epistèmôn) y "ciencia divina" (theía tôn epistèmôn). 10 Pues bien, el ser humano puede acceder a esta "ciencia divina" porque su lógos está vinculado y subordinado al nô̂s, a la inteligencia como facultad de conocimiento teorético, que Platón y Aristóteles ensalzan como la parte divina e inmortal del ser humano. El bios theōrētikós es más virtuoso, feliz y admirable que el bios praktikós, porque la theōría es la más sublime de todas las actividades humanas, la que eleva al ser humano hasta la libre e inmortal divinidad y lo separa de la esclava y mortal existencia animal.

Por último, la definición del ser humano como "animal político" no solo está restringida a determinadas categorías de seres humanos y subordinada a su otra definición como "animal dotado de lógos", sino que además estas dos limitaciones,

\footnotetext{
8 Aristóteles, Política 1253a 7-18.

9 Aristóteles, Ética a Nicómaco, Libro VI, 1138b 18 - 1145a 11. Para la traducción, Aristóteles (2002), pp. 88-102.

10 Aristóteles, Metafísica, Libro I, 980a 21 - 983b 6, pp. 2-20, y Libro IV, 1003a 21 - 1006a 34. Para la traducción, Aristóteles (1982), pp. 150-169.
} 
a pesar de que responden a un determinado régimen histórico-político de jerarquización estamental, son expresamente naturalizadas y, de este modo, legitimadas como incuestionables, pues Aristóteles afirma reiteradamente que la pertenencia a una polis dividida estamentalmente y la doble facultad del lógos y el nô̂s les son dadas al ser humano "por naturaleza" (physei) y no "por casualidad" (tychēi). Ahora bien, si el ser humano es un animal político "por naturaleza", eso significa que lo es "por nacimiento", de forma necesaria (anankē) e inherente a su ser o sustancia (ousía) y no de forma azarosa (tychē) y extrínseca, como sucede con las cualidades artificiales que adquiere o le son impuestas desde fuera, sea por algún hábito (héxis), aprendizaje (paideía) o costumbre (nómos), o sea por la invención y el uso de alguna prótesis o suplemento técnico (téchnē), pues ambos tipos de artificio dependen de la libre elección humana (proaíresis) y, por tanto, son históricamente contingentes y variables.

En resumen, la definición aristotélica del ser humano como "animal político" sufre en el propio Aristóteles una triple limitación: por su restricción a ciertas categorías de seres humanos; por su subordinación al lógos, al noûs, a la epistémē, en fin, a la divina actividad de conocimiento; $y$, por último, por la naturalización de las dos operaciones anteriores. Y esta triple limitación tuvo enormes consecuencias en la historia del pensamiento filosófico, científico y político de Occidente. De hecho, la historia del pensamiento occidental, durante más de dos milenios, ha sido la historia de un gran proceso de despolitización, es decir, de naturalización y, por tanto, de legitimación ideológica de unos determinados regímenes histórico-políticos de dominación estamental entre diferentes categorías de seres humanos.

La Política de Aristóteles es un texto mucho más rico y complejo de lo que parece a primera vista, y además no ha cesado de sufrir toda clase de interpretaciones durante más de dos milenios. En mi opinión, es la obra que más influencia ha tenido en la historia de la teoría y la práctica políticas de Occidente. No me es posible recordar aquí los principales avatares de esa larga historia, pero conviene tenerlos muy en cuenta para comprender adecuadamente la relectura que hace Hannah Arendt de la Política de Aristóteles, y en particular de su doble definición del ser humano como "animal político" (zôion politikón) y como "animal dotado de logos" (zôion lógon échon).

Como es sabido, el pensamiento de Hannah Arendt estuvo orientado a cuestionar la tradición dominante del pensamiento filosófico occidental, procedente de Platón y Aristóteles, y en particular la jerarquía antropológica entre el conocimiento y la acción, entre el bíos theōrētikós y el bios praktikós, entre la filosofía y la 
política. Frente a esta tradición filosófica epistemocéntrica, Arendt se propuso reivindicar la vida práctica o política como la forma de vida más distintiva y eminentemente humana. Ahora bien, ella consideraba, conforme a un viejo prejuicio eurocéntrico que nunca puso en cuestión, que esta exaltación de la vida humana como vida política fue una invención de la Grecia clásica, y que a partir de la experiencia griega se inició en Occidente una tradición paralela a la que ha sido dominante hasta ahora, una "tradición oculta" que ha ido apareciendo y desapareciendo de forma discontinua, y que ha tenido sus momentos de esplendor en las antiguas fundaciones de ciudades, en las modernas revoluciones políticas y en los movimientos cívicos de las últimas décadas. 11

En su intento por recuperar la experiencia griega, ocupa un lugar muy destacado la lectura que hace de los textos éticos y políticos de Aristóteles. Por un lado, Arendt reivindica la definición aristotélica del ser humano como "animal político" y la distinción entre la sociabilidad gregaria de otras especies animales y la sociabilidad propiamente política, que está vinculada al lógos y que por tanto es específicamente humana. Pero, por otro lado, Arendt rechaza la pretensión -que unas veces atribuye al propio Aristóteles y otras veces a sus intérpretes "modernos"- de que esa condición política le es dada al ser humano por naturaleza, por nacimiento, por necesidad, como una cualidad que se transmitiría genéticamente y que por tanto sería inherente a la constitución biológica de todos y cada uno de los seres humanos individuales. Una de las tesis fundamentales de Arendt es que la comunidad política no es una realidad naturalmente dada, sino convencionalmente instituida: solo puede surgir allí donde se reúne una pluralidad de seres humanos singulares y libres, es decir, en el espacio intermedio que se crea entre unos y otros, en el entre que a un tiempo los junta y los separa, en la red de interacciones e interlocuciones que van tejiendo libremente unos con otros, y cuyo entramado da lugar a instituciones comunes más o menos duraderas.

Podemos estar de acuerdo con Arendt en su afirmación de que la comunidad política no es una realidad naturalmente dada, sino históricamente instituida, es decir, que no depende de ninguna necesidad o ley natural, sino de la libertad humana y de las leyes políticas, esto es, de los acuerdos deliberados entre una pluralidad de seres singulares, unos acuerdos que son siempre contingentes, precarios y cambiantes.

Ahora bien, conviene llevar cuidado con esta vieja contraposición metafísica entre necesidad y libertad, a la que Arendt recurre con demasiada facilidad. Por un lado, Arendt es consciente de que no puede afirmarse en serio la libertad humana si no se cuestiona al mismo tiempo la concepción determinista de la naturaleza, que

11 De los muchos estudios sobre Arendt, me limitaré a citar los de tres autoras cuya interpretación del pensamiento arendtiano me parece especialmente fecunda: Forti (2001), Sánchez (2003) y Birulés (2007). 
según ella ha prevalecido en la historia del pensamiento filosófico, teológico y científico de Occidente. Por eso, en los últimos párrafos de su ensayo "¿Qué es la libertad?", tras definir la libertad humana como la capacidad de dar inicio a algo nuevo en el mundo, más aún, como la capacidad de hacer "milagros" (en la medida en que un "milagro" es la "improbabilidad infinita" de que algo suceda), Arendt vincula expresamente esta concepción de la libertad con la concepción indeterminista de la naturaleza, y afirma que toda la historia de la naturaleza es una sucesión de milagros: la formación del sistema solar, el surgimiento de la vida orgánica en el planeta Tierra y, por último, la aparición del ser humano a partir de la evolución de otras especies animales. 12

Pero, por otro lado, y de forma contradictoria, Arendt recurre constantemente a la contraposición entre necesidad y libertad, como dos órdenes ontológicos diferentes: por un lado, la realidad natural, que sería el orden de la necesidad; por otro lado, la realidad humana, que sería el orden de la libertad. Según Arendt, nuestra vida estaría escindida entre estos dos órdenes: el de la necesidad natural y el de la libertad política.

Pues bien, a mí me parece que esta oposición entre necesidad y libertad es una de esas "falacias metafísicas" que la propia Arendt pretendía denunciar. Y el hecho de que ella la haya aceptado sin discusión, es lo que le impide comprender adecuadamente la relación entre vida y política, no solo en su interpretación de la Política de Aristóteles, sino también en su diagnóstico crítico sobre el Occidente moderno.

Los seres humanos, como los demás seres vivos, nacemos y morimos en un mundo que nos precede y nos sobrevive. El nacimiento y la muerte son los límites irrebasables y las condiciones de posibilidad de la vida humana. Pero los humanos no nos limitamos a experimentar pasivamente esos dos límites naturales, como unas determinaciones biológicas que nos son impuestas y que por tanto exceden a nuestra capacidad de decisión, sino que podemos actuar libremente con respecto a ellas: podemos cuidar y preservar la vida que nos ha sido dada, y al mismo tiempo evitar o demorar la muerte que nos está destinada; pero también podemos descuidar y arriesgar nuestra vida, e incluso buscar o provocar nuestra propia muerte. Más aún, no solo podemos actuar en relación con nuestra vida y nuestra muerte, sino también en relación con las de los demás: no solo nacemos y morimos, sino que también podemos dar la vida y la muerte a otros seres humanos, y, en general, a otros seres vivos. Esta doble capacidad de dar la vida y la muerte a otros seres vivos es el fundamento ontológico de ese fenómeno al que llamamos poder. Todo poder es un

12 Arendt (1996), pp. 155-184. 
poder ser o no-ser, un poder de creación y destrucción, un hacer que algo llegue a ser o deje de ser. Por eso, el Dios todopoderoso de la teología cristiana es el único Ser eterno y necesario, en la medida en que puede crear y destruir a todos los otros seres. Si adoptamos la terminología de Foucault, habría dos grandes formas de poder: el poder como "derecho de vida y de muerte", que consiste ante todo en la capacidad de matar a otros o amenazarlos de muerte, con el fin de atemorizarlos y obtener así su sometimiento; y el poder como "administración de la vida", que consiste ante todo en engendrar, alimentar, proteger, cuidar, adiestrar y potenciar la vida de aquellos seres a los que se gobierna.

Pues bien, Arendt define la vida política, en cuanto relación libre e igualitaria entre seres heterogéneos y singulares, como un espacio intermedio entre esos dos extremos de la vida humana que son el nacimiento y la muerte, dos extremos que según ella aíslan y uniformizan a los humanos en cuanto meros seres vivos:

La experiencia de la vida y de la muerte, no solo se da en aislamiento, sino en total soledad, donde no es posible la verdadera comunicación, y mucho menos la asociación y comunidad. Desde el punto de vista del mundo y de la esfera pública, la vida y la muerte y todo lo que atestigua uniformidad son experiencias no mundanas, antipolíticas y verdaderamente trascendentes. 13

Para Arendt, la vida política es un fin en sí misma, no un medio o instrumento al servicio de la supervivencia, sea que ese instrumento se use para cuidar la vida en tiempo de paz o para defender la libertad en tiempo de guerra. Tanto la reproducción y el mantenimiento de la vida, como la lucha a muerte para defender la libertad, son condiciones "pre-políticas" de la vida política, porque permiten liberarse de las "necesidades vitales", en el primer caso, y de la "dominación violenta", en el segundo caso. Pero, según Arendt, una cosa son las actividades que hacen posible la liberación de esa doble coacción vinculada al nacimiento y la muerte -como el sometimiento de mujeres y esclavos en el ámbito doméstico, y el sometimiento de otros pueblos por medio de la guerra- y otra cosa es el ejercicio ocioso y pacífico de la libertad, que es la actividad política propiamente dicha. Por eso, según Arendt, la vida política no es coextensiva con la vida humana, no se da en cualquier tiempo y lugar en donde los seres humanos conviven en sociedades históricamente constituidas, sea cual sea el régimen de convivencia que adopten. Esta manera de interpretar la definición aristotélica del ser humano como "animal político", dice Arendt, es un "prejuicio moderno" y se basa en un "malentendido", porque para Aristóteles -y para los griegos en general- no todos los seres humanos son políticos, y tampoco lo son todos los regímenes de convivencia, sino solo los ciudadanos libres de las ciudades helenas que se rigen por la isonomía. Pero lo más relevante es que Arendt

13 Arendt (1993), pp. 236-237. 
adopta como propia esta concepción de la política -a la vez restringida y normativa- que atribuye a Aristóteles y a la mayoría de los griegos:

Lo que distinguía la convivencia humana en la pólis de otras formas de convivencia humana que los griegos conocían muy bien era la libertad (...) Para ser libre, el hombre debía ser liberado o liberarse él mismo, y este estar libre de las obligaciones necesarias para vivir era el sentido propio del griego scholé o del romano otium, el ocio, como decimos hoy. Esta liberación, a diferencia de la libertad, era un fin que podía y debía conseguirse a través de determinados medios. El decisivo era el esclavismo, la violencia con que se obligaba a que otros asumieran la penuria de la vida diaria (...) Los Antiguos explotaban a los esclavos para liberar completamente a los señores de la labor [Arbeit], de manera que estos pudieran entregarse a la libertad de lo político. Esta liberación se conseguía por medio de la coacción y la violencia, y se basaba en la dominación absoluta que cada amo ejercía en su casa. Pero esta dominación no era ella misma política, aun cuando representaba una condición indispensable para todo lo político. ${ }^{14}$

Arendt rechaza "el prejuicio moderno de que la política es una necesidad ineludible y de que la ha habido siempre y por doquier", y en cambio reivindica lo que ella considera que es el sentido aristotélico y griego de la política:

Precisamente necesario -sea en el sentido de una exigencia ineludible de la naturaleza humana como el hambre o el amor, sea en el sentido de una organización indispensable de la convivencia humana- lo político no lo es, puesto que solo empieza donde acaba el reino de las necesidades materiales y la violencia física. Tan poco ha existido siempre y por doquier lo político como tal que, desde un punto de vista histórico, solamente unas pocas grandes épocas lo han conocido y hecho realidad. ${ }^{15}$

Así entendida, la vida política es una modalidad excepcional de la vida humana, pues cobra forma tangible únicamente en unos pocos lugares y períodos de la historia: Arendt los llama "islas en el mar" y "oasis en el desierto". Como dice en Sobre la revolución, el objetivo de la élite de hombres libres, al imponer su dominación colectiva sobre los estamentos sometidos y los pueblos colonizados, es "proteger la isla de libertad en que habitan contra el mar de necesidad que les rodea". 16 La vida política es una especie de territorio franco, instituido y sostenido precariamente, destinado a sufrir el acoso permanente de esos dos enemigos opuestos que son, por un lado, la "necesidad" natural, vinculada a la reproducción y mantenimiento de la vida, y, por otro lado, la "violencia" organizada, vinculada a la guerra y la dominación coactiva.

\footnotetext{
14 Arendt (1997), p. 69; (2008), p. 152.

15 Arendt (1997), p. 71; (2008), pp. 154-155.

16 Arendt (1988), p. 286.
} 
La vida política se funda en la libertad. Y la libertad solo puede ejercerse, según Arendt, cuando una comunidad de individuos se ha liberado de una doble coerción: por un lado, el sometimiento a las necesidades de la vida, a las exigencias biológicas que conlleva su reproducción, su cuidado y su sustento; por otro lado, el sometimiento a la violencia de la muerte, al riesgo siempre posible de ser exterminado, esclavizado y dominado coactivamente por otros. La libertad se afirma contra esa doble coerción, la que nos impone la necesidad vital y la que nos impone la violencia mortal.

Por eso, dice Arendt, "la valentía es la primera de todas las virtudes políticas". 17 La valentía es la virtud de los hombres libres, porque es la demostración de que están dispuestos a arriesgar y sacrificar su propia vida, y a luchar sin miedo contra los tiranos internos o los enemigos externos, para defender frente a ellos no su mera supervivencia, sino más bien su vida política, su condición de hombres libres. En cambio, el esclavo es el que está dispuesto a perder su libertad y a doblegarse ante otros, por un exceso de amor a la vida y temor a la muerte. Por cierto, el término latino de virtus, procedente de vir (varón), alude a la valentía o fortaleza de ánimo, como una cualidad de los varones libres, que en cambio estaría ausente en las mujeres, recluidas en el hogar y dedicadas a la reproducción y cuidado de la vida:

Dejar la casa, originalmente con el fin de embarcarse en alguna aventurada y gloriosa empresa [guerrera o comercial] y posteriormente solo para dedicar la propia vida a los asuntos de la ciudad, requería valor, ya que sólo allí [en la casa] predominaba el interés por la supervivencia personal. 18

En resumen, frente a la doble afirmación de Aristóteles (“...que la pólis es una realidad natural y que el ser humano es por naturaleza un animal político"), y a lo que Arendt llama la interpretación "moderna" de esa doble afirmación, ella pretende desnaturalizar completamente la vida política, definiéndola como un espacio convencionalmente instituido por una pluralidad de agentes libres. Pero esa desnaturalización de la política tiene como reverso la despolitización de la vida, al considerar como condiciones "a-políticas" o "pre-políticas" no solo los límites naturales de la vida humana -el nacimiento y la muerte-, sino también el modo en que esos límites son regulados, desplazados, modificados y socialmente distribuidos por los propios seres humanos, mediante actividades que son a un tiempo, inseparablemente, práxis y téchnē. En efecto, para Arendt, la vida política "solo empieza donde acaba el reino de las necesidades materiales y la violencia física", es decir, que deja fuera de sí todo cuanto hace posible la existencia misma de la vida política, más

17 Arendt (1997), p. 73; (2008), p. 157.

18 Arendt (1993), p. 47. 
aún, todo cuanto condiciona las diferentes modalidades o regímenes internos de esa vida política.

Por eso, a pesar de rechazar la naturalización de la política postulada por Aristóteles, acepta sin reservas, como si se tratase de un universal antropológico, la restricción aristotélica de la política al espacio público de la pólis, y, con ella, la dicotomía entre el oíkos y la pólis. Más aún, Arendt radicaliza esa dicotomía y le atribuye un sentido que no se corresponde con el pensamiento del filósofo griego. Para Aristóteles, tanto la familia como la ciudad son comunidades o asociaciones naturales; además, dentro de la familia, distingue dos formas de asociación que son igualmente naturales: la parental (entre hombres y mujeres) y la señorial (entre amos y esclavos); todas estas formas de asociación son igualmente necesarias para la vida del ser humano, porque todas ellas responden a diferentes necesidades naturales: la reproducción sexuada, el sustento económico y la defensa armada; y si hay una jerarquía entre ellas, es porque la ciudad reúne a varias familias y aldeas, y además cumple con una finalidad que la familia no puede cumplir, como es la defensa del territorio y, en general, la autarquía o soberanía bélica frente a otras comunidades territoriales, que es el supremo fin de la comunidad política. Para Aristóteles, hay un continuo entre el nacimiento y la muerte, es decir, entre esas tres actividades humanas que son la reproducción, el sustento y la guerra; por tanto, hay también un continuo entre la naturaleza y la política. La diferencia fundamental entre oíkos y pólis no es, como pretende Arendt, la diferencia entre necesidad y libertad, ni tampoco entre las actividades solitarias de la labor y el trabajo, y las actividades comunitarias de la acción y la palabra, sino entre las distintas comunidades y categorías de seres humanos que realizan unas y otras actividades, es decir, entre el gobierno despótico que el padre y patrón ejerce sobre la mujer, los hijos, los esclavos y los animales en el espacio privado del oíkos, y el gobierno entre iguales que los cabezas de familia ejercen en el espacio público de la pólis.

Arendt, pese a su crítica de los "prejuicios modernos", asume una dicotomía ontológica acuñada por el racionalismo moderno, como es la contraposición kantiana entre el reino de la necesidad natural y el reino de la libertad moral, y la proyecta retrospectivamente sobre la antigua dicotomía griega entre oíkos y pólis:

Ser político, vivir en una pólis, significaba que todo se decía por medio de palabras y de persuasión, y no con la fuerza y la violencia. Para el modo de pensar griego, obligar a las personas por medio de la violencia, mandar en vez de persuadir, eran formas prepolíticas para tratar con la gente cuya existencia estaba al margen de la pólis, [dentro] del hogar y de la vida familiar, con ese tipo de gente en que el cabeza de familia gobernaba con poderes despóticos e indisputados, o bien con los bárbaros de Asia, cuyo despotismo era a menudo señalado como semejante a la organización de la familia.

La definición aristotélica del hombre como zôion politikón no sólo no guardaba relación, sino que se oponía a la asociación natural experimentada en la vida familiar; úni- 
camente se la puede entender por completo si añadimos su segunda definición del hombre como zôion lógon échon ("ser vivo capaz de discurso"). ${ }^{19}$

(...)

Lo que dieron por sentado todos los filósofos griegos, fuera cual fuera su oposición a la vida de la pólis, es que la libertad se localiza exclusivamente en la esfera política, que la necesidad es de manera fundamental un fenómeno prepolítico, característico de la organización doméstica privada, y que la fuerza y la violencia se justifican en esta esfera [y en las relaciones de guerra y de dominación sobre otras comunidades, sean bárbaras o helenas] porque son los únicos medios para dominar la necesidad -por ejemplo, gobernando a los esclavos- y llegar a ser libre. ${ }^{20}$

Al identificar la contraposición de "todos los filósofos griegos" entre oíkos y pólis con la contraposición postulada por Kant y otros muchos filósofos modernos entre necesidad y libertad, Arendt malinterpreta otra conocida distinción aristotélica (malentendida también por numerosos intérpretes, desde la Edad Media hasta hoy) entre la mera "vida" (es decir, la reproducción y el sustento, garantizados por el oíkos) y la "buena vida" (es decir, la autarquía o soberanía territorial, garantizada por la pólis):

La "buena vida", como Aristóteles califica a la del ciudadano, no era simplemente mejor, más libre de cuidados o más noble que la ordinaria, sino de una calidad diferente por completo. Era "buena" en el grado en que, habiendo dominado las necesidades de la pura vida, liberándose de trabajo y labor, y vencido el innato apremio de todas las criaturas vivas por su propia supervivencia, ya no estaba ligada al proceso biológico vital. 21

Para Aristóteles, tanto la familia como la ciudad son "comunidades naturales", y cada una de ellas responde a una finalidad o necesidad natural del ser humano. Lo que ocurre es que Aristóteles establece entre ellas una jerarquía y una secuencia teleológica que conduce de la una a la otra: la comunidad de hombre y mujer hace posible la reproducción sexuada, la comunidad de amo y esclavo hace posible el sustento económico, y la comunidad de varias familias y aldeas hace posible la autarquía o soberanía militar sobre un determinado territorio e incluso la hegemonía imperial sobre las colonias de ultramar y sobre las ciudades aliadas o sometidas, por medio de la violencia armada. El ejercicio de la violencia no queda fuera de la política, como dice Arendt, sino que para Aristóteles y para los griegos en general es una actividad consustancial a la vida política: por un lado, la violencia despótica ejercida hacia los subordinados tanto en el interior del oíkos como en el interior de

\footnotetext{
19 Arendt (1993), p. 40.

20 Arendt (1993), pp. 43-44.

21 Arendt (1993), p. 47.
} 
la pólis (mujeres, esclavos, metecos, etc.); por otro lado, la violencia armada ejercida hacia otras comunidades políticas (bárbaros o helenos, enemigos o colonizados). Y si la valentía es la principal virtud política, lo es precisamente porque está ligada al ejercicio de esa doble violencia que se requiere en la dominación despótica sobre los subordinados y en el enfrentamiento guerrero con los enemigos. En resumen, la pólis o comunidad político-militar es la comunidad perfecta porque subsume a las otras formas de comunidad y les añade el fin supremo de la autarquía o soberanía territorial, es decir, porque solo en ella se cumplen todas las finalidades o necesidades naturales de la vida humana. Para Aristóteles, el "vivir bien" proporcionado por la pólis se refiere precisamente al disfrute de esta autarquía o soberanía político-militar por parte de los ciudadanos libres. La autarquía es el máximo ideal ético y político, porque sin ella los ciudadanos libres podrían convertirse en esclavos de otros, sea de algún tirano o de algún pueblo extranjero. Pero el ciudadano libre solo puede conseguir la autarquía sojuzgando a otros: sean los miembros de la comunidad familiar (mujer, hijos, esclavos y animales), sean los esclavos extranjeros o las colonias y los pueblos sometidos.

Lo sorprendente es que Arendt califique como "a-políticas" o "pre-políticas" todas estas relaciones de violencia y dominación, sea en el interior de la familia y la ciudad (entre diferentes estamentos sociales), sea en el exterior de la ciudad (entre diferentes comunidades políticas), y que las sitúe en un "estado de naturaleza" en el que no regiría ninguna convención socio-política, ni habría tampoco libertad alguna, sino la imperativa fuerza de la necesidad vital y la imperativa fuerza de la violencia mortal.

Desde el momento en que Arendt mistifica el régimen estamental de la antigua pólis griega y lo convierte en un universal antropológico, más exactamente, desde el momento en que despolitiza todas las actividades y relaciones sociales vinculadas con la administración (a un tiempo técnica y política) de la vida y la muerte, esto condiciona completamente su interpretación de la historia de las sociedades humanas.

Por un lado, el hecho de que atribuya a los griegos la invención de la política es un prejuicio eurocéntrico, más aún, es un supuesto fundamental de esa tradición dominante del pensamiento político occidental que Arendt se propuso problematizar, una tradición que ha estado vigente desde Platón hasta Hegel, y que tras el nacimiento de las ciencias sociales ha persistido en el llamado evolucionismo social. Las sucesivas conquistas colonizadoras de los helenos, los romanos y los europeos modernos, se justificaron con este argumento: los "bárbaros" y los "salvajes" viven 
en "estado de naturaleza" porque carecen de una civilización como la "nuestra". Arendt llega a decir que las sociedades tribales no son comunidades políticas, porque "los factores que rigen sus acciones y su conducta son las necesidades vitales y la preservación de la vida, y no la libertad". 22 Sin embargo, hoy sabemos que han sido "las primeras sociedades de la abundancia", porque en ellas el trabajo destinado a la satisfacción de las necesidades vitales ocupa solo cuatro o cinco horas diarias, la jornada laboral más baja de toda la historia. ${ }^{23}$ Además, son las primeras sociedades igualitarias que conocemos: en ellas no hay división entre el oíkos y la pólis, porque toda la comunidad trabaja y disfruta del ocio. En este sentido, el concepto arendtiano de "comunidad política" se ajusta a estas sociedades mucho más que a la pólis griega. Pierre Clastres las denomina "sociedades contra el Estado", y, en abierta polémica con el estatismo eurocéntrico de Hobbes, considera que son verdaderas comunidades políticas, en las que el poder no es usurpado por una élite gobernante sino que es ejercido por el conjunto de la comunidad.24

Por otro lado, el hecho de que Arendt restrinja la política a ese espacio acotado en el que se relacionan como seres libres e iguales los privilegiados ciudadanos del Estado-ciudad heleno, el hecho de que convierta en un ideal normativo la división jerárquica entre el oíkos y la pólis, basada en la "pre-política" división estamental entre diferentes categorías de seres humanos, es lo que le lleva a interpretar negativamente la Modernidad occidental (es decir, la economía capitalista, el Estadonación soberano y el poder transformador de los saberes tecno-científicos), como una nefasta inversión de lo que ella considera que es la correcta jerarquía antropológica entre las distintas esferas de la vida (labor, trabajo y acción), es decir, como una subordinación de la pólis al oíkos, de la necesidad a la libertad, y de la política a la vida:

Para nosotros [los modernos] esta línea divisoria [entre lo privado y lo público, la familia y el Estado, la vida y la política] ha quedado borrada por completo, ya que vemos el conjunto de pueblos y comunidades políticas a imagen de una familia cuyos asuntos cotidianos han de ser cuidados por una administración doméstica gigantesca y de alcance nacional. El pensamiento científico que corresponde a este desarrollo ya no es ciencia política, sino "economía nacional" o "economía social" o Volkswirtschaft, todo lo cual indica una especie de "administración doméstica colectiva" [Arendt toma esta expresión del economista Gunnar Myrdal, al que cita]; el conjunto de familias económicamente organizadas en el facsímil de una familia superhumana es lo que llamamos "sociedad", y su forma política de organización se califica con el nombre de "nación". Por lo tanto, nos resulta difícil comprender que, según el pensamiento antiguo sobre

\footnotetext{
22 Arendt (1996), p. 160.

23 Sahlins (1977).

24 Clastres (1978 y 1981).
} 
estas materias, la expresión "economía política" habría sido una contradicción de términos: cualquier cosa que fuera "económica", en relación a la vida del individuo y a la supervivencia de la especie, era no política, se trataba por definición de un asunto familiar. ${ }^{25}$

(...)

En el Mundo Moderno, las esferas social y política están mucho menos diferenciadas. Que la política no es más que una función de la sociedad, que acción, discurso y pensamiento son fundamentalmente superestructuras relativas al interés social, no es un descubrimiento de Karl Marx, sino que, por el contrario, es uno de los supuestos que dicho autor aceptó de los economistas políticos de la Edad Moderna. Esta funcionalización hace imposible captar cualquier seria diferencia entre las dos esferas; no se trata de una teoría o ideología, puesto que con el ascenso de la sociedad, esto es, del "conjunto doméstico" (oikía), o de las actividades económicas a la esfera pública, la administración de la casa y todas las materias que anteriormente pertenecían a la esfera privada familiar se han convertido en interés "colectivo". En el Mundo Moderno, las dos esferas fluyen de manera constante una sobre la otra, como olas de la nunca inactiva corriente del propio proceso de la vida.

La desaparición de la zanja que los antiguos tenían que saltar para superar la estrecha esfera doméstica y adentrarse en la política es esencialmente un fenómeno moderno. ${ }^{26}$

Si la política surge en Grecia como una despolitización de la vida, de modo que las actividades y relaciones sociales vinculadas con el nacimiento y la muerte serían "pre-políticas", la Modernidad se caracteriza, por el contrario, por una biologización de la política, de modo que todas esas actividades y relaciones invaden el espacio político, lo que supone que la política se subordina a la vida y la libertad se somete a la necesidad. Esta moderna biologización del ser humano se da en el ámbito de la convivencia política, en donde la "economía política" se convierte en el nuevo arte de gobernar y el ser humano deja de ser un animal político y se convierte en un animal laborans, dedicado exclusivamente a producir y consumir los bienes necesarios para su sustento vital; pero se da también, de forma paralela y entrecruzada, en el ámbito del conocimiento científico y técnico, en donde el ser humano deja de ser un agente libre, un sujeto ético-político, y se convierte en un ser vivo entre otros, es decir, en un objeto susceptible de ser investigado científicamente y manipulado técnicamente, lo que ha dado lugar a dos situaciones extremas en el siglo XX: por un lado, el exterminio programado de millones de seres humanos (sea en los regímenes totalitarios, o sea en la nueva época inaugurada por las armas de destrucción masiva, que pueden exterminar a toda la humanidad); por otro lado, la posibilidad de manipular el genoma humano, con el fin de prevenir enfermedades y "prolongar la vida humana más allá del límite de los cien años", pero también con

25 Arendt (1993), p. 42.
26 Arendt (1993), p. 45. 
el fin de mejorar artificialmente las características naturales de la especie humana y "producir seres humanos superiores".27

Arendt aplica el diagnóstico de la biologización de la política al conjunto de la Modernidad, pero considera que sus tendencias de fondo llegaron a un punto extremo en el siglo XX, primero con los campos de exterminio 28 y las armas de destrucción masiva, y después con los desarrollos de la ingeniería genética y la biomedicina. 29

Arendt practica el método analítico, en el sentido etimológico del término análisis, que es de origen griego y significa descomponer un ser o un fenómeno en sus elementos constitutivos; pero no lo complementa con el método sintético, también en el sentido griego del término síntesis, que significa conjunción o composición de los elemento constitutivos de ese ser o fenómeno. ${ }^{30}$ En su fenomenología de la condición humana, Arendt se esfuerza en diferenciar netamente los elementos constitutivos que la integran: la vita contemplativa (descompuesta en tres actividades mentales: pensamiento, voluntad y juicio) y la vita activa (descompuesta en tres actividades corporales: labor, trabajo y acción). Pero, no satisfecha con aislar y diferenciar analíticamente esos diversos elementos, mediante un procedimiento de abstracción y simplificación conceptual, propone normativamente que la forma de vida más propiamente humana es aquella en la que los distintos elementos que la integran deben permanecer completamente separados, descompuestos y meramente yuxtapuestos entre sí, como si se tratase de compartimentos estancos. Arendt no comprende que la vida humana solo es propiamente humana precisamente cuando se da la conjunción, combinación o síntesis inseparable de los diversos elementos que la constituyen.

\footnotetext{
27 Arendt (1993), p. 15.

28 Arendt (2005), pp. 295-296.

29 Arendt (1993), pp. 14-15.

30 La palabra análisis es de origen griego, derivada del verbo analeo y compuesta del prefijo ana-, que indica un movimiento en dirección a lo originario, lo elemental, lo principal, y del sustantivo -lisis, que significa disolución, descomposición, desligamiento, separación, liberación de las ataduras. Así, pues, analizar algo es desanudarlo, desenredarlo, a fin de separar o liberar los elementos constitutivos que en él se encuentran mezclados o trabados. En este sentido, el análisis sigue un movimiento inverso al de la síntesis, otro término de origen griego, cuyo prefijo sin- indica composición, conjunción, reunión de lo que estaba previamente separado. Los prefijos de origen griego $\sin$ - y ana-, contrapuestos y complementarios entre sí, tienen su equivalente semántico en los prefijos de origen latino com/cons- y de/s-, en expresiones como componer y descomponer, construir y destruir (o desconstruir).
} 
Podemos analizar las moléculas de agua y descomponerlas en los átomos que las integran (dos átomos de hidrógeno y uno de oxígeno), pero si mantuviéramos separados y meramente yuxtapuestos esos dos elementos químicos, ya no tendríamos agua sino hidrógeno y oxígeno, precisamente porque el agua surge y consiste en la conjunción, combinación o síntesis de los diversos elementos que la constituyen.

Arendt fragmenta al ser humano como si pudiera y debiera llevar tres vidas separadas: la del animal laborans (que se ocupa del mantenimiento de su propio cuerpo viviente, pero también del cuerpo viviente de los que conviven con él, cosa que Arendt no tiene en cuenta), la del homo faber (que se dedica a fabricar o producir técnicamente un mundo de objetos artificiales más o menos duraderos), y la del zôion politikón (que se dedica exclusivamente a conversar y regular libremente sus relaciones con sus semejantes). Sin embargo, el ser humano es un compuesto inseparablemente bio-tecno-político, y no habría vida propiamente humana si no se diera la conjunción, combinación o síntesis del animal laborans, el homo faber y el zôion politikón.

Lo que sucede es que el modo en que han de combinarse entre sí estas tres dimensiones de la vida humana no está determinado de una vez por todas, como sucede en la molécula de agua, sino que caben muchas combinaciones posibles. De hecho, se han dado combinaciones muy diversas en la historia de las sociedades humanas.

Y el problema es que allí donde hay relaciones de dominación entre unos seres humanos y otros, suele instituirse una especialización "funcional", es decir, una (des)articulación patológica entre estos tres ámbitos de la vida humana y entre las diferentes categorías de seres humanos "especializados" en cada una de ellos. Por ejemplo, las mujeres y los esclavos son forzados a especializarse en la reproducción y mantenimiento de la vida (la propia y la de los otros); los artesanos, artistas e ingenieros se especializan en la fabricación de toda clase de objetos artificiales (sean útiles o meramente suntuarios), y los jefes políticos y militares se especializan en la organización, potenciación y gobierno de las comunidades humanas (dirigiendo tanto sus asuntos internos como sus relaciones con otras comunidades).

Por eso, habría que replantear de otro modo el ideal político republicano defendido por Arendt. No podemos seguir concibiendo la vida política como un ámbito sublime, casi celeste, restringido a un territorio acotado y a unos pocos elegidos que se dedicarían al cultivo ocioso de la "acción" y la "palabra", tras haberse liberado de esas otras ocupaciones más terrenales, el "trabajo" y la "labor", propias de los estamentos sociales sometidos, que estarían condenados a ocuparse exclusivamente de su supervivencia y la de los demás. No podemos seguir entendiendo la vida política como un "oasis" asediado por el "desierto", es decir, por la doble amenaza de las necesidades vitales y la violencia organizada. Por el contrario, hemos de encontrar la manera de politizar todos los ámbitos y todas las escalas de nuestra vida 
cotidiana.

Hemos de inventar nuevas formas de convivencia en donde todos los seres humanos podamos cultivar y compatibilizar las diferentes dimensiones de nuestra vida (la reproducción sexuada, el sustento económico, la deliberación colectiva, la creación y transmisión del pensamiento simbólico), aprendiendo a construir juntos la mejor síntesis posible entre todas ellas. Además, hemos de hacerlo en nuestras diferentes escalas de interacción social, tecnológica y ecológica, desde las pequeñas comunidades familiares y vecinales hasta las grandes comunidades nacionales, continentales y mundiales, puesto que unas y otras se encuentran cada vez más entretejidas en una sola red global que conecta a todos los seres humanos entre sí y con el resto de los seres vivientes.

Algunos filósofos griegos - como Demócrito de Abdera y Diógenes de Sinopeya intuyeron que los humanos no somos "animales políticos", sino más bien "animales cosmo-poli-éticos", y que por tanto hemos de encontrar la mejor manera de conciliar éthos, pólis y kósmos, es decir, nuestra subjetividad ética, nuestra convivencia política y nuestra pertenencia a un mundo que nos precede, nos sustenta y nos sobrevive.

\section{Referencias bibliográficas}

ARENDT, H. (1981): Los orígenes del totalitarismo, 3 vols., trad. de Guillermo Solana, Madrid, Alianza, orig. inglés 1951.

Arendt, H. (1988): Sobre la revolución, trad. de Pedro Bravo, Madrid, Alianza.

ARENDT, H. (1993): La condición humana, trad. de Ramón Gil Novales, intr. de Manuel Cruz, Barcelona, Paidós, orig. inglés 1958.

ARENDt, H. (1996): Entre el pasado y el futuro. Ocho ejercicios sobre la reflexión política, trad. de Ana Luisa Poljak Zorzut, Barcelona, Península.

Arendt, H. (1997): ¿Qué es la política?, introd. de Fina Birulés, trad. de Rosa Sala, Barcelona, Paidós/ICE de la UAB, orig. alemán 1993.

ARENDt, H. (2005): Ensayos de comprensión 1930-1954, trad. de Agustín Serrano de Haro, Madrid, Caparrós.

Arendt, H. (2008): La promesa de la política, trad. de Eduardo Cañas y Fina Birulés, Barcelona, Paidós, orig. inglés 2005.

Aristóteles (1971): Politique, ed. bilingüe griego-francés de Jean Aubonnet, Paris, Les Belles Lettres, tomo II, primera parte.

ARISTÓTELES (1982): Metafísica, ed. trilingüe griego-latín-español de Valentín García Yebra, Madrid, Gredos, $2^{\mathrm{a}}$ ed. revis.

ARISTóteles (1983): Política, ed. bilingüe griego-español de María Araujo y Julián Marías, Madrid, Centro de Estudios Constitucionales, $2^{\mathrm{a}} \mathrm{ed}$. 
Aristóteles (1988): Política, ed. de Manuela García Valdés, Madrid, Gredos.

ARISTÓteles (2002): Ética a Nicómaco, ed. bilingüe griego-español de María Araujo y Julián Marías, introd. y notas de J. Marías, Madrid, Centro de Estudios Políticos y Constitucionales, $2^{\mathrm{a}}$ ed.

Aristóteles (2004): Política, ed. de Carlos García Gual y Aurelio Pérez Jiménez, Madrid, Tecnos, $3^{\mathrm{a}}$ ed.

Birulés, F. (2007): Una herencia sin testamento: Hannah Arendt, Barcelona, Herder.

CAmpillo, A. (2001): El gran experimento. Ensayos sobre la sociedad global, Madrid, Los Libros de la Catarata.

CAmpillo, A. (2010): "Biopolítica, totalitarismo y globalización", Barcelona Metrópolis, 78, pp. 40-47.

Clastres, P. (1978): La sociedad contra el Estado, trad. de Ana Pizarro, Caracas/Barcelona, Monte Ávila. Reeditado, con trad. de Paco Madrid e intr. de Beltrán Roca Martínez, en Barcelona, Virus, 2010.

Clastres, P. (1981): Investigaciones en antropología politica, trad. de Estela Ocampo, Barcelona, Gedisa.

ForTI, S. (2001): Vida del espíritu y tiempo de la polis: Hannah Arendt entre filosofia y politica, trad. Irene Romera y Miguel Ángel Vega, rev. Fina Birulés, Madrid, Cátedra / Universitat de València.

Foucault, M. (1978): Historia de la sexualidad I. La voluntad de saber, trad. de Ulises Guiñazú, Madrid, Siglo XXI, orig. francés 1976.

SAHLins, M. (1977): Economía de la Edad de Piedra, trad. de Emilio Muñiz y Erna Rosa Fondevila, Madrid, Akal.

SÁnchez, C. (2003): Hannah Arendt: el espacio público, Madrid, Centro de Estudios Políticos y Constitucionales.

Antonio Campillo

Facultad de Filosofía

Universidad de Murcia

campillo@um.es 